\title{
Effect of Explosive Properties on the Energy Distribution of Blasting Seismic Waves in Carbonate Rocks
}

\author{
Ming-shou Zhong ${ }^{1, ~ a, ~ Q u a n-m i n ~ X i e ~}{ }^{2, b}$, Tao Guo ${ }^{1, c}$, Ying Liu ${ }^{1, d}$, Hao-quan Liu ${ }^{1, e}$ \\ ${ }^{1}$ University of Science \& Technology of PLA, Nanjing 210007, China; \\ ${ }^{2}$ Wuhan Ornance N.C.O. Academy of PLA, Wuhan 430075, China.

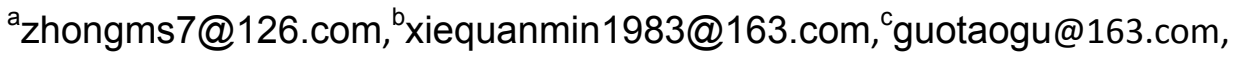 \\ 'Liuying@126.com, ${ }^{\mathrm{e} H a o-q u a n @ s i n a . c o m ~}$
}

Keywords: carbonate Rocks,blasting Seismic Waves,explosive exploration.

\begin{abstract}
This template explains and demonstrates how to prepare your camera-ready paper for Trans Tech Publications. The best is to read these instructions and follow the outline of this text. Please make the page settings of your word processor to A4 format $(21 \times 29,7 \mathrm{~cm}$ or $8 \times 11$ inches); with the margins: bottom $1.5 \mathrm{~cm}(0.59 \mathrm{in})$ and top $2.5 \mathrm{~cm}(0.98 \mathrm{in}), \mathrm{right} / \mathrm{left}$ margins must be $2 \mathrm{~cm}$ (0.78 in). This template explains
\end{abstract}

\section{Introduction}

Seismic wave signal analysis is not olnythe most important part in the development of petroleum exploration and development, but also the key to determine the position of oil and natural gas in the rock.Because of the seismic wave signals haveimportant informationsuch as lithology, physical properties, oil and gas, which are usually reflected in the characteristics of its spectrum. So,the fine signal processing technology is conducive for improving the signal to noise ratio of seismic exploration seismic exploration, and providing data support for the accurate prediction of oil and gas exploration.

\section{2 lifting wavelet packet algorithm principle}

\subsection{Decomposition algorithm [1-3]:}

(1) Split:Split the coefficeiernt of $(j, n)$ node $\left(n=1,2, \cdots, 2^{j}\right)$ into oddcoefficeiernt $d_{n o}^{j}$ and evencoefficeiernt $d_{n e}^{j}$.

(2)Predict:The coefficient of $(j+1,2 n)$ node can be obtained by formula (1).

$$
d_{2 n}^{j+1}[k]=d_{n o}^{j}[k]-\sum_{l=1}^{N} p[l] d_{n e}^{j}[k+l-N]
$$

(3)Update: The coefficient of $(j+1,2 n+1)$ node can be obtained by formula (2).

$$
d_{2 n+1}^{j+1}[k]=d_{n e}^{j}[k]+\sum_{i=1}^{\tilde{N}} u[l] d_{2 n}^{j+1}[k+l-\tilde{N}](2)
$$

Where, $\quad p[l], l=1,2, \cdots, N$ is predictor coefficient, $u[l], l=1,2, \cdots, \hat{N}$ isupdate coefficient.

\subsection{Reconstruction algorithm [1-3]:}

(1) Inverse update:Evencoefficeiernt of $(j, n)$ can be obtained bycoefficeierntof $(j+1,2 n)$ and $(j+1,2 n+1)$.

$$
d_{n e}^{j}[k]=d_{2 n+1}^{j+1}[k]-\sum_{i=1}^{\tilde{N}} u[l] d_{2 n}^{j+1}[k+l-\tilde{N}]
$$

(2)Inversepredict: Oddcoefficeiernt of $(j, n)$ can be obtained bycoefficeierntof $(j+1,2 n+1)$ and $(j, n)$.

$$
d_{n o}^{j}[k]=d_{2 n}^{j+1}[k]+\sum_{i=1}^{N} p[l] d_{n e}^{j}[k+l-N]
$$

(3)Merge: Coefficeiernt of $d_{n}^{j}$ can bemerged by $d_{n o}^{j}, d_{n e}^{j}$. 


\section{Energy distribution of blasting seismic waves}

Energy distribution of explosion seismic wave signals can be carried out in accordance with the following steps.First, the seismic wave signal will be decomposed into the jlayer,set $E_{j, k}$ is the corresponding energy for $S_{j, k}$ :

$$
E_{9, j}=\int\left|S_{j, i}\right|^{2} d t=\sum_{i=1}^{m}\left|x_{j, i}\right|^{2}(5)
$$

Where, $x_{j, i}$ is amplitude of the discrete points for the reconstructed signal $S_{j, k}$. Set the total energy of the signal is $E_{0}$, then

$$
E_{0}=\sum_{i=0}^{2^{j}-1} E_{j, i}(6)
$$

The proportion of the total energy of each frequency band can be obtained byformula (7).

Where, $i=0,1,2, \cdots, 2^{j}-1$.

$$
E_{i}=\frac{E_{j, i}}{E_{0}} \times 100 \%(7)
$$

\section{Effect of explosive properties on the energy distribution of seismic waves}

\subsection{Comparison of energy distribution of single channel seismic wave signal}

In typical carbonate rocks, the seismic wave signal were measured by emulsion explosive,TNT andRDX, whichare three kinds of explosives used in seismic exploration. Three dimensional energy spectra of the fifteenth seismic wave signals was shown in Figure 1.The total energy and the energy of each band by the emulsion explosive are smaller than those of TNT and RDX, but the low frequency energy of seismic wave signal is relatively more abundant.

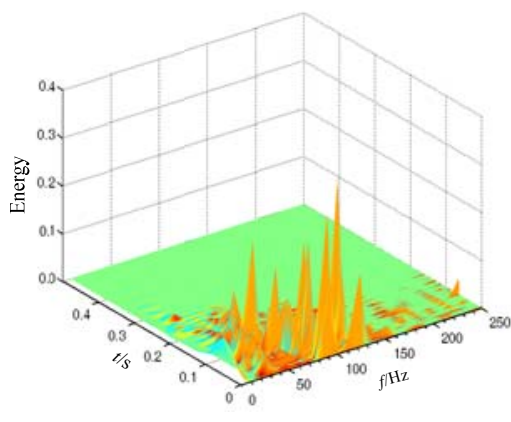

(a)emulsion explosive

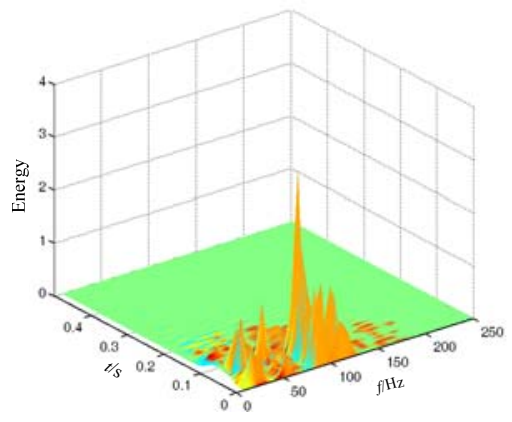

(b) TNT

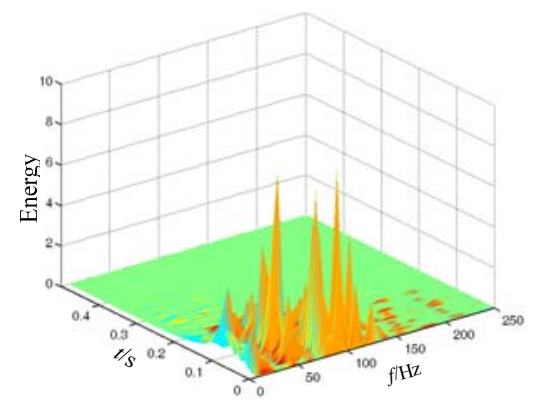

(c) RDX

Fig.1 Three dimensional energy spectrum of single channel seismic wave signal

with different explosive properties

When the three kinds of explosive charge are excited, the fifteenth channel seismic wave signals were analyzed to improve the data statistics of the energy distribution of the frequency bands after wavelet packet decomposition and reconstruction.For comparison, the seismic wave signals were divided into 6 frequency bands. Among them, the low frequency of $0-10 \mathrm{~Hz}$ and $80-250 \mathrm{~Hz}$ of high frequency interference signals were very weak, the percentage of the total energy was smaller.Most of the signal energy was concentrated in the range of $10-80 \mathrm{~Hz}$. The emulsion explosive was $69.2 \%$, TNT was 51.4\% and RDX was $67.8 \%$.However, the total energy difference of seismic wave signal is very small, when TNT and RDXexcited. 
Table 1 Energy distribution of the single channel seismic wave signal in different explosives

\begin{tabular}{cccccccc}
\hline \multirow{2}{*}{$\begin{array}{c}\text { frequency } \\
\text { channel }\end{array}$} & $\begin{array}{c}\text { Frequency } \\
\text { band } / \mathrm{Hz}\end{array}$ & \multicolumn{2}{c}{ Emulsion explosive } & \multicolumn{3}{c}{ TNT } & \multicolumn{2}{c}{ RDX } \\
\cline { 3 - 8 } & $\begin{array}{c}\text { Energy } \\
\text { value/(cm/s) }\end{array}$ & $\begin{array}{c}\text { Energy } \\
\text { percentage } / \%\end{array}$ & $\begin{array}{c}\text { Energy value } \\
/(\mathrm{cm} / \mathrm{s})^{2}\end{array}$ & $\begin{array}{c}\text { Energy } \\
\text { percentage } / \%\end{array}$ & $\begin{array}{c}\text { Energy value } \\
/(\mathrm{cm} / \mathrm{s})^{2}\end{array}$ & $\begin{array}{c}\text { Energy } \\
\text { percentage } / \%\end{array}$ \\
\hline 1 & $0-10$ & 0.0147 & 0.02 & 0.3224 & 0.08 & 0.3695 & 0.09 \\
2 & $10-80$ & 64.786 & 69.2 & 216.41 & 51.44 & 296.11 & 67.87 \\
3 & $80-130$ & 22.613 & 24.2 & 178.31 & 42.38 & 114.05 & 26.14 \\
5 & $130-190$ & 0.3441 & 0.37 & 0.2947 & 0.07 & 0.4965 & 0.11 \\
6 & $190-220$ & 5.3356 & 5.70 & 20.194 & 4.80 & 17.732 & 4.07 \\
Full band & $220-250$ & 0.4760 & 0.51 & 5.1842 & 1.23 & 7.5131 & 1.72 \\
\hline
\end{tabular}

Fig.2 is a comparison between the energy and the energy of each band of the single channel seismic wave signal.It can be seen from the figure, although total energy and effective reflection wave band energy of the seismic wave signal are lower than that of TNT and RDX, but energy of the effective reflection band is higher than that of the source.Because of the larger proportion of effective frequency band energy, the signal to noise ratio is higher, so the result of the analysis fifteenth channel seismic wave can be used to improve the seismic excitation effect.
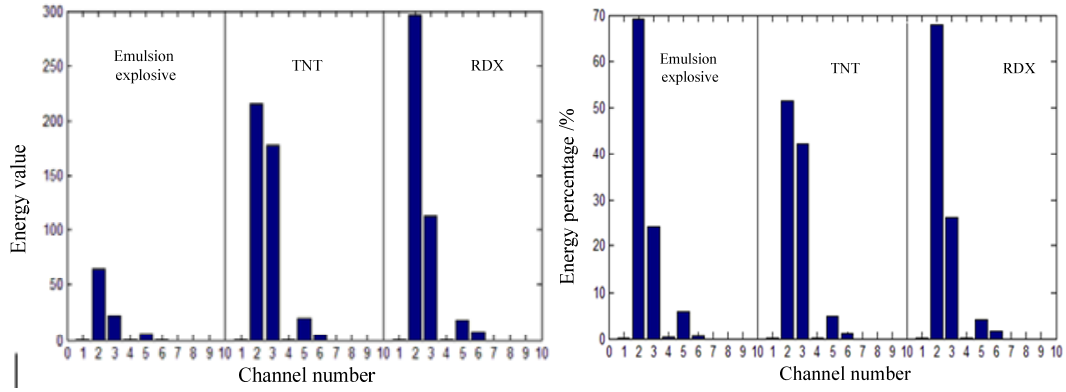

(a) Distributionhistogramof energy values(b) Distribution histogram of energy ratio values

Fig.2 Band energy histogram of seismic wave signal

\subsection{Comparison of energy distribution of multi channel seismic wave signals}

In order to study the energy distribution characteristics of seismic wave signals measured at different distances, $1 、 5 、 10 、 20 、 25 、 30 、 35 、 40 、 45 、 50 、 55 、 60 、 65 、 70$ channel seismic wave signals of three kinds of different loading sources were also analyzed by lifting wavelet packet transform.Data statistics results were shown in table 2.Total energy values of the signals from each channel were analyzed. RDX and TNT's signal energy of each channel was morethanemulsion explosive's. Total energy of seismic wave signal of TNT and RDX with the source explosiveis more and more close to the distance, and the energy values between $10 \mathrm{~Hz}$ to $80 \mathrm{~Hz}$ are also close to.

Table 2 Frequency band energy value and distribution ratio of multi channel seismic wave signal in different explosive

\begin{tabular}{cccccccccc}
\hline & \multicolumn{3}{c}{ Emulsion explosive } & \multicolumn{3}{c}{ TNT } & & \multicolumn{2}{c}{ RDX } \\
\cline { 2 - 10 } $\begin{array}{c}\text { Channel } \\
\text { number }\end{array}$ & $\begin{array}{c}\text { Total } \\
\text { energy }\end{array}$ & $\begin{array}{c}10-80 \mathrm{~Hz} \\
\text { Energy } \\
\text { value }\end{array}$ & $\begin{array}{c}\text { Energy } \\
\text { percentage } \\
\text { /\% }\end{array}$ & $\begin{array}{c}\text { Total } \\
\text { energy }\end{array}$ & $\begin{array}{c}10-80 \mathrm{~Hz} \\
\text { Energy } \\
\text { value }\end{array}$ & $\begin{array}{c}\text { Energy } \\
\text { percentage } \\
\text { /\% }\end{array}$ & $\begin{array}{c}\text { Total } \\
\text { energy }\end{array}$ & $\begin{array}{c}10-80 \\
\text { Energy } \\
\text { value }\end{array}$ & $\begin{array}{c}\text { Energy } \\
\text { percentage } \\
/ \%\end{array}$ \\
\hline 1 & 299.8 & 247.9 & 82.7 & 2770.6 & 1434.1 & 51.8 & 1460.4 & 899.8 & 61.6 \\
5 & 739.5 & 535.2 & 72.4 & 2848.9 & 2089.2 & 71.3 & 2240.1 & 1556.8 & 69.4 \\
10 & 387.2 & 258.3 & 66.7 & 1437.2 & 904.2 & 62.9 & 1149.3 & 733.5 & 63.8 \\
15 & 93.6 & 64.8 & 69.2 & 420.7 & 216.6 & 51.5 & 436.3 & 296.3 & 67.9 \\
20 & 46.9 & 30.2 & 64.6 & 106.9 & 58.9 & 55.1 & 334.7 & 199.3 & 59.5 \\
25 & 108.8 & 48.7 & 44.8 & 200.9 & 53.4 & 26.6 & 597.5 & 184.2 & 30.8 \\
30 & 29.7 & 24.2 & 81.6 & 67.4 & 37.4 & 55.5 & 115.2 & 71.4 & 61.9 \\
35 & 47.8 & 18.2 & 38.0 & 141.3 & 38.7 & 27.4 & 245.4 & 72.4 & 29.5 \\
40 & 85.3 & 59.5 & 69.7 & 155.4 & 103.2 & 66.4 & 178.7 & 125.0 & 69.6 \\
\hline
\end{tabular}




\begin{tabular}{cccccccccc}
\hline 45 & 5.3 & 2.8 & 50.6 & 20.2 & 9.4 & 46.5 & 23.8 & 9.9 & 41.6 \\
50 & 31.1 & 24.9 & 80.3 & 87.9 & 60.9 & 69.3 & 90.6 & 65.3 & 72.1 \\
55 & 2.5 & 1.8 & 72.7 & 11.1 & 7.2 & 64.9 & 10.9 & 7.5 & 69.3 \\
60 & 7.0 & 5.3 & 75.2 & 33.3 & 16.1 & 48.4 & 31.8 & 19.1 & 59.8 \\
65 & 19.1 & 12.8 & 67.4 & 102.0 & 57.0 & 55.9 & 86.8 & 52.4 & 60.3 \\
70 & 23.4 & 13.5 & 57.6 & 75.5 & 35.0 & 46.4 & 81.2 & 37.3 & 46.0 \\
\hline
\end{tabular}

The attenuation of seismic wave signal energy with different channelin the three kinds of explosive were shown in Fig.3 It can be seen that the overall trend of the three sets of signal decreases with the increase of the detector.Before the $30^{\text {th }}$ channel, their energy difference was relatively large, but the signal energy was getting closer and closer, due to the absorption of the formation of the high frequency,due to rock layers can absorb high frequency bandsin seismic waves.

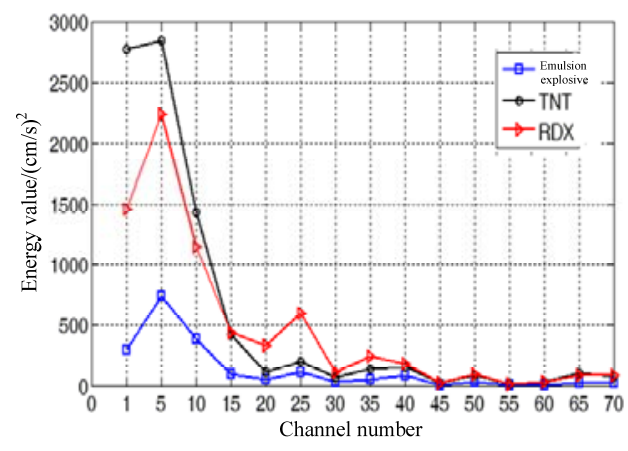

Fig.3 Relationship between the energy of seismic wave signal and the distance

\section{Summary}

In carbonate rocks, the signal to noise ratio of the seismic exploration test signal can be improved by using emulsion explosive as the source of TNT and RDX. The use of low efficiency of explosives is conducive to improving the excitation effect, and the energy shortage can increase the amount of the source to improve the exploration results.

\section{Acknowledgments}

Project fund: National Natural Science Foundation of China (51304218); Natural Science Foundation of Jiangsu province (BK20151449).

\section{References}

[1] WimSweldens. The Lifting Scheme: A Construction of Second Generation Wavelets [J]. SIMA J Math Anal, 1996,29(2): 511-546.

[2] Daubechies I, Sweldens W. Factoring wavelet transforms into lifting steps. Journal of Fourier Analysis and Application, 1998, 4(3): 247-269.

[3] Sweldens w. The Lifting Scheme: A Custom-Design Construction of Biorthogonal Wavelets [J]. Applied and Computational Harmonic Analysis, 1996, 15(3): 186-200. 